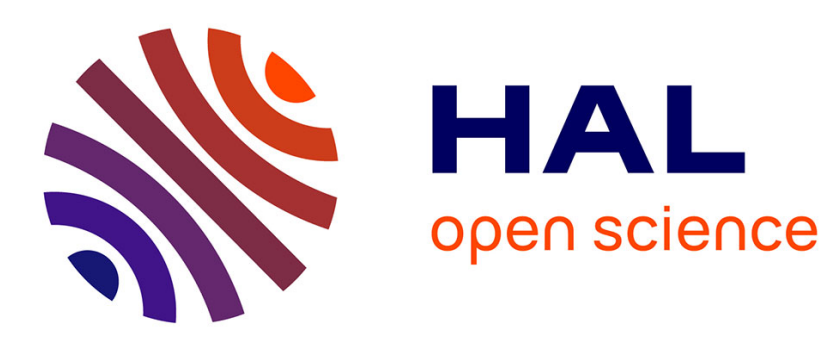

\title{
Deposition of $\mathrm{ZrO} 2$ and Y2O3-stabilized $\mathrm{ZrO} 2$ from $\beta$-diketonates
}

\author{
M. Pulver, G. Wahl, H. Scheytt, M. Sommer
}

\section{To cite this version:}

M. Pulver, G. Wahl, H. Scheytt, M. Sommer. Deposition of $\mathrm{ZrO} 2$ and Y2O3-stabilized $\mathrm{ZrO} 2$ from $\beta$-diketonates. Journal de Physique IV Proceedings, 1993, 03 (C3), pp.C3-305-C3-312. 10.1051/jp4:1993342 . jpa-00251399

\section{HAL Id: jpa-00251399 https://hal.science/jpa-00251399}

Submitted on 1 Jan 1993

HAL is a multi-disciplinary open access archive for the deposit and dissemination of scientific research documents, whether they are published or not. The documents may come from teaching and research institutions in France or abroad, or from public or private research centers.
L'archive ouverte pluridisciplinaire HAL, est destinée au dépôt et à la diffusion de documents scientifiques de niveau recherche, publiés ou non, émanant des établissements d'enseignement et de recherche français ou étrangers, des laboratoires publics ou privés. 


\title{
Deposition of $\mathrm{ZrO}_{2}$ and $\mathrm{Y}_{2} \mathrm{O}_{3}$-stabilized $\mathrm{ZrO}_{2}$ from $\beta$-diketonates
}

\author{
M. PULVER, G. WAHL, H. SCHEYTT* and M. SOMMER* \\ Institut für Oberflächentechnik, Technische Universität Braunschweig, Bienroder Weg 53, \\ 38108 Braunschweig, Germany \\ * ASEA Brown Boveri AG, CRH, Eppelheimer Str. 82, 69123 Heidelberg, Germany
}

\begin{abstract}
The deposition of $\mathrm{ZrO}_{2}$ and $\mathrm{Y}_{2} \mathrm{O}_{3}$-stabilized $\mathrm{ZrO}_{2}$ from metalorganic B-diketonates by CVD and the evaporation behaviour of those precursors was investigated. Evaporation and deposition processes were correlated with fluiddynamical calculations and found to be in good agreement. The calculations also show that much higher growth rates than achieved until now could be expected (i.e. $>1 \mu \mathrm{m} / \mathrm{min}$ ).
\end{abstract}

\section{Introduction}

Zirconia $\left(\mathrm{ZrO}_{2}\right)$ has interesting physical and chemical properties, which can be used for particular technical applications. An excellent resistance against temperature changes and the low thermal conductivity allow the use as a heat barrier in furnaces, reactors, turbines etc.. The conductivity for oxygen anions is the reason for the application of zirconia as a solid-state electrolyte in fuel cells. For high temperature applications the cubic phase of zirconia is necessary, which is normally stable at about $1000^{\circ} \mathrm{C}$. The stabilization of the desired phase is achieved by adding yttria. The deposition of zirconia and yttria-stabilized zirconia (YSZ) is possible by plasma spraying techniques, CVD (=chemical vapour deposition) or ECVD (=electroCVD). By plasma spraying one can easily generate thick films $(0,1 \ldots$ several $\mathrm{mm})$, but they often have insufficient properties for particular applications like a deficient adhesion or a heterogeneous layer structure. The ECVD method only works with very small deposition rates in the range of several $\mu \mathrm{m} / \mathrm{h}$. It has been used to deposit thin YSZ layers on porous substrates for the application in fuel cells $/ 1$. The technique of conventional CVD offers the possibility to deposit high quality layers with well defined properties in adequate periods of time. Calculations of the deposition rate show that it is possible to reach deposition rates in the range of $\mu \mathrm{m} / \mathrm{min}$ by the use of an appropriate process technique /2/. One key point is the enrichment of the precursor in the gas phase, which should be as high as possible but without the formation of powder in the gas phase. Calculations for the YBCO-deposition show that it could be expected to increase the deposition rate simply by raising the precursor concentration in the gas phase $/ 3 /$.

\section{Experimental equipment}

For the evaporation experiments of the precursors the microbalance arrangement shown in fig. 1 was used. This equipment mainly consists of three parts: the gas supply, the evaporator and the microbalance, which is connected to the evaporator via a magnetic suspension coupling (Rubotherm, Bochum, FRG). The evaporator consists of a stainless steel tube with an internal diameter of $60 \mathrm{~mm}$, which was equipped with a resistance heating. Inside this tube the vessel 
with the precursor is hung up at the coupling. The evaporation temperature was measured inside the tube just above the rim of the vessel by the use of a $\mathrm{NiCr} / \mathrm{Ni}$-thermocouple. The weight of the vessel with the precursor was transferred via the coupling to the microbalance (Mettler, type AT261) and collected online by a computer.

The carrier gas (argon) flows from the bottom of the evaporator to the top with a flow rate of 20 $1 / \mathrm{h}$ (STP). The measurements were carried out at a typical pressure of $p=1000 \mathrm{~Pa}$, which is also the working pressure of the CVD experiments. According to /4/ at the pressure of $1000 \mathrm{~Pa}$ no temperature fluctuation in the gas atmosphere should appear, which could result from a vertical temperature profile in the tube and disturb the measurement. Evaporation temperature was varied between $120^{\circ} \mathrm{C}$ and $240^{\circ} \mathrm{C}$.

The gas flow from the microbalance evaporator was piped directly into a cooling trap. All tubes between the evaporator and the cooling trap were heated up to a temperature about 20 degrees higher than the evaporation temperature in order to supress condensation.

Three types of evaporation vessels have been used which are made of an aluminium alloy and have an inner diameter of $28 \mathrm{~mm}$ so that they all have the same cross section. The difference is the height of the wall, which is for the types $a, b$ and c 28, 14 and $2 \mathrm{~mm}$ respectively, leading to a different formation of the diffusion boundary layer during the evaporation. The filling height in each case was $2 \mathrm{~mm}$.

The CVD arrangement for the deposition experiments is identical to that described for the deposition of the high-Tc-superconductors $/ 5 /$. The main part is a stagnation flow reactor with cold walls in which the substrate holder is heated inductively using an RF-generator. The usage of the stagnation flow geometry guarantees a homogeneous mass transport to the substrate surface if the gas flow conditions are suitable. The cold wall design suppresses reactions of the reactive species in the gas and a deposition on the reactor walls. The deposition experiments were carried out at a total pressure of $p=1000 \mathrm{~Pa}$. For all experiments the gasflow in the reactor was $60 \mathrm{l} / \mathrm{h}$ STP, whereby the oxygen gasflow varied between $10 \mathrm{l} / \mathrm{h}$ and $40 \mathrm{l} / \mathrm{h} \mathrm{STP}$. As substrate material single crystal (111)-oriented Si was used $\left(10 \times 10 \mathrm{~mm}^{2}\right)$.

\section{Precursor materials}

The applicability of a CVD process strongly depends on the availability of precursors, which carry the elements to be deposited onto the substrate. Such a suitable compound should have a high vapour pressure in the temperature range up to $300^{\circ} \mathrm{C}$ and it has to be stable in the gas phase at these temperatures. At the deposition temperature on the contrary the precursor has to decompose readily and completely without the deposition of residuals which could decrease the layer's quality.

A well known group of metal-organic compounds with acceptable physical and chemical properties are the B-diketonates. Their low evaporation temperature and the thermal stability have led to a widespread use of these chelate compounds in CVD processes, e.g. the deposition of superconductors of the YBCO-type /5/. In our experiments we used the 2.2.6.6-tetramethylheptane-3.5-dionates of zirconium and yttrium as precursors. These were purchased from different companies (here distinguished as A and B). These compounds are converted into the corresponding oxides by reaction with elemental oxygen, which form the desired layer.

\section{Microbalance experiments}

In fig. 2 a typical evaporation curve of $\mathrm{Zr}(\mathrm{tmhd})_{4}$ (from supplier A) at a temperature of $180^{\circ} \mathrm{C}$ is 
shown measured with vessel a (i.e. height of wall $=28 \mathrm{~mm}$ ). During the heating-up period a characteristic weight loss was observed due to the evaporation of small amounts of residual solvent of the manufacture process of the precursor. After 30 minutes the desired temperature in the evaporator system is reached. The very small decrease in the evaporation rate of about $0,5 \% / \mathrm{h}$ can be explained by the change of the filling height of the precursor in the vessel. The measured evaporation rate keeps nearly constant for about 8 hours, but then drops for the reason of draining off the vessel. At lower temperatures $\left(160^{\circ} \mathrm{C}\right)$ the evaporation rate is even constant for more than 24 hours. The corresponding values for the charge of supplier $\mathrm{B}$ were $\mathrm{a}$ decrease of $3,4 \% / \mathrm{h}$ at $180^{\circ} \mathrm{C}$ and about $1 \% / \mathrm{h}$ at $160^{\circ} \mathrm{C}$.

The temperature dependence obtained from the microbalance experiments are shown in fig. 3 , where the molar evaporation rates of the investigated precursors are plotted in a logarithmic scale versus the reciprocal evaporation temperature. The activation energy for the precursor from supplier $A$ is significantly smaller then that of supplier $B$, which results in a stronger temperature dependence of the evaporation rate.These evaporation experiments were all carried out with the evaporation vessel type a.

The evaporation rates increased strongly when we used the evaporation vessel $\mathrm{c}$ with the lowest wall (i.e. $2 \mathrm{~mm}$ ). This is caused by the different gas flow pattern in the evaporation geometry. The crucible a possesses high walls which are nearly as high as its inner diameter. Inside the vessel a stagnant gas layer is formed, which acts as a diffusion boundary layer with the thickness $\delta$, which is in the range of the depth of the vessel. In this region the transport of the precursor only takes place by diffusion. Using the evaporator $c$ the argon gas flow has direct contact to the precursor powder. The diffusion boundary layer is reduced to a minimum extend $(\delta \approx 1 \mathrm{~mm})$ determinated by the gas velocity. The constant evaporation rates described above can only be reached with the evaporator a. In this case the relative change in the distance between the above edge of the vessel and the surface of the powder is small. So the evaporation rate limiting step of the diffusion is not strongly influenced by changing the filling level. On the contrary the distance of the powder surface to the vessel rim in the evaporator $c$ increases relatively strong during the evaporation and the evaporation rate decreases. The evaporation rate achieved with vessel $b$ is about $70 \%$ higher then for type a by reason of the smaller boundary layer, but it is nearly three times lower than for type $c$.

The dependence of the evaporation rates on the total pressure has also been investigated for our compounds. In fig. 4 the molar evaporation rate is plotted versus the reciprocal pressure. As can be seen from the plot fig. 4 the evaporation rates are proportional to the reciprocal total pressure. This dependence can be expected at a constant evaporator geometry and at a constant Reynolds number Re and Schmidt number Sc $/ 6 /$.

\section{Deposition experiments}

Fig. 5 shows the growth rates s of YSZ versus the reciprocal deposition temperature. At temperatures below $610^{\circ} \mathrm{C}$ the deposition of $Y S Z$ is kinetically controlled. From the temperature dependency an activation energy of $E_{A}=51.2 \mathrm{~kJ} / \mathrm{mol}$ was derived. In this region the deposition is controlled by the kinetics of the thermal decomposition of the molecules on the heated substrate surface. The deposition rate of YSZ becomes independent of the deposition temperature for temperatures above $610^{\circ} \mathrm{C}$. In this region the deposition rate is limited by the mass transport of the molecules towards the substrate. The maximum deposition rate was about $1 \mu \mathrm{m} / \mathrm{h}$ due to the small precursor concentration in the gas phase (molar fraction $\sim 10^{-4}$ ) we applied for the deposition experiments until now.

The single oxide deposition was investigated, too. For the deposition of zirconia from $\mathrm{Zr}(\mathrm{tmhd})_{4}$ 
a transition temperature of $630{ }^{\circ} \mathrm{C}$ between the reaction and the diffusion controlled range was found. The activation energy was $80 \mathrm{~kJ} / \mathrm{mol}$. The deposition of $\mathrm{Y}_{2} \mathrm{O}_{3}$ is temperature dependent at temperatures below $500^{\circ} \mathrm{C}$ with an activation energy of $180 \mathrm{~kJ} / \mathrm{mol}$.

The deposition rate is also strongly dependent on the partial pressure of oxygen. At very high oxygen concentrations (i.e. $>50 \%$ ) the deposition of powdery zirconia was observed. This is due to a decomposition of the $\mathrm{Zr}(\mathrm{tmhd})_{4}$ in the gas phase and has been formerly noted for the CVD with $\mathrm{ZrCl}_{4}$, too /7/.

A comparison between the deposition of YSZ, zirconia and yttria, concerning the deposition rate and the activation energy shows that the deposition of the YSZ results as a superposition of the deposition of the single oxides. This is not surprising because of the random distribution of the $\mathrm{Zr}$ and $\mathrm{Y}$ in the $\mathrm{YSZ}$. The ratio of the deposition rates yttria:zirconia is proportional to the evaporation rates of the particular precursors $\mathrm{Zr}(\mathrm{tmhd})_{4}: Y(\operatorname{tmhd})_{3}$. Because of the different temperature dependence of the deposition of zirconia and yttria the composition of the deposited YSZ layer is also temperature dependent at lower temperatures (i.e. $<600^{\circ} \mathrm{C}$ ).

\section{Fluid dynamic calculations}

By the use of a computer program for fluid flow modeling the evaporation behaviour in our microbalance arrangement and the deposition in the stagnation flow reactor was simulated. This program FLUENT (version 3.03, creare.x inc.,1991) is suited for modeling complex internal and external flows encountered in chemical and process engineering equipment. FLUENT uses a finite difference numerical procedure to solve the fundamental equations governing flow (the Navier-Stokes equations). Additional equations are taken into account for the parameters of the chemical species and the enthalpy.

The diffusion coefficients were calculated by Fluent from the kinetic theory according to the following equation $/ 3 /$ :

$$
D_{i j}=0,002628 \frac{\sqrt{T^{3} \frac{\left(M_{i}+M_{j}\right)}{2 M_{i} M_{j}}}}{p \sigma_{i j}^{2} \Omega_{i j}^{(1.1)^{*}} \frac{\epsilon_{i j}}{k}}
$$

with: the diffusion coefficient $D_{i j}$ in $\mathrm{cm}^{2} / \mathrm{s}$, the total pressure $\mathrm{p}$ in atm, the temperature $T$ in $K$, the molar masses $M_{i}, M_{j}$ in $\mathrm{g} / \mathrm{mol}$, the Lennard Jones lenght $\sigma_{i j}$ in $\AA$, the Lennard Jones energy $\varepsilon_{i j} / k$ ( $k=$ Boltzmann constant) and the reduced collision integrals $\Omega_{\mathrm{ij}}$. The Lennard Jones parameter for Argon were taken from /8/. For $\mathrm{Zr}(\mathrm{tmhd})_{4}$ the values for $\mathrm{Y}(\mathrm{tmhd})_{3}$ were taken, which are also given by /3/: $\quad \sigma_{\mathrm{ij}}=10,7 \AA \quad \varepsilon_{\mathrm{ij}} / \mathrm{k}=600 \mathrm{~K}$

For these calculations it was assumed that directly above the surface of the precursor the equilibrium vapour pressure $p_{\theta}$ of the compound is reached. The comparison of the experimental evaporation rate and the precursor mass flux derived from the fluid dynamic calculations leads to a value of the vapour pressure of the compound above the surface.

Such a calculation of the vapour pressure was performed for the experimental results with all the three evaporation vessels type $a, b$ and $c$. The values showed good accordance $( \pm 20 \%)$ and confirmed the correctness of the assumption of the formation of the vapour pressure $p_{\theta}$ above the precursor surface.

In addition we compared our results for the vapour pressure of $\mathrm{Zr}(\mathrm{tmhd})_{4}$ with the vapour pressure given by likawa et al. 19/, who have measured the vapour pressure of several B- 
diketonates and gave the following equation for $\mathrm{Zr}(\mathrm{tmhd})_{4}$ (vapour pressure in Torr, temperature in $\mathrm{K})$ : $\log P=-3687 / T+7,659$

As can be seen from fig. 6 there is a difference in the evaporation behaviour between the values of $/ 9 /$ and the results we found for the samples $A$ and $B$. Below temperatures of $220^{\circ} \mathrm{C}$ we got significantly lower equilibrium vapour pressures then they did. This may be due to a different quality of the compounds which leads to a different evaporation behaviour with another temperature dependence of the evaporation rate.

In fig. 7 the calculated evaporation rates for the different filling heights are compared to the measured ones. The vapour pressure determined with vessel a was used for the calculations.

The gas flow pattern caused by the geometry of vessel a is shown in fig. 8 . As can be seen from the calculated flow velocity vectors there is a penetration of the gas flow to the upper half of the vessel. The flow velocity in this part is in the range of several $\mathrm{cm} / \mathrm{s}$ and is approximately as high as the diffusion velocity, assessed by the approximation $v=D / s$ with the distance $s$ and the diffusion coefficient $\mathrm{D}$.

In the diffusion limited range the deposition rate can be calculated, too. This calculation was performed according to the methods described in $/ 3 /$. The result of such a calculation for the deposition of YSZ is shown in fig. 5 and is in good accordance with the experimental results. The considerations also lead to the conclusion that the low deposition rate is dependent on a low precursor concentration in the gas phase. An increase of the rate is possible by raising the concentration.

\section{Discussion}

$\mathrm{Zr}$ (tmhd $)_{4}$ is well suited for an application as precursor for MOCVD of zirconia. It is stable up to temperatures of at least $240^{\circ} \mathrm{C}$ and guarantees a stable evaporation rate for long-time deposition experiments. A further increase however is limited by a thermal decomposition, which takes place at $300^{\circ} \mathrm{C} / 9 /$. In the case of $Y(t m h d)_{3}$ the change in the evaporation rate with time is more significantly especially at temperatures higher than $160^{\circ} \mathrm{C}$ (i.e. $~ 2 \% / h$ ), but this may be due to the quality of our precursor batch. The strong dependence of the stability of the B-diketonates and other precursors on the synthesis is well known $/ 10 /$.

The difference in the evaporation behaviour in the three types of vessels can be explained easily with the appearance of different thicknesses of the stagnant gas layer. The contributions of diffusion and convection to the evaporation can be simulated by flow modeling calculations.

As can be seen from the high partial pressures of $Z r(t m h d)_{4}$ shown in fig. 6 , it is possible to reach high enough precursor concentrations in the gas phase. In addition an optimal planning of the evaporator is needed especially with regard to the gas flow conditions and the active surface area to reach high and long-time stable evaporation rates.

\section{Conclusions}

The microbalance equipment is an useful instrument for the investigation of the evaporation behaviour of compounds for the use in CVD processes. One can easily measure the dependence of the evaporation rate of the different process parameters. It is also possible to determine the vapor pressure of the precursors.

Fluid dynamic calculations are suitable for the modeling of the flow phenomena in CVD proces- 
ses for the evaporation of the precursors as well as for the deposition of the films.

The combination of both the microbalance measurements and the flow calculations makes it possible to estimate the influence of the reactor design on the process and to optimize the reactor geometry.

The maximum concentration of the precursor in the gas atmosphere is given by the equilibrium vapour pressure and can only be approached by optimized evaporation conditions. As could be seen from the comparison of the evaporation behaviour of the different vessels the evaporation geometry has to meet the following requirements:

- $\quad$ In order to reach a high evaporation rate the diffusion boundary layer has to be kept as low as possible.

- $\quad$ The gas flow should not be influenced by changing the filling level. In our case the surface and level of the precursor powder has to be kept constant to guarantee a constant evaporation rate.

These demands could be fulfilled for example with a powder transport system in which the precursor is transferred constantly from a stock of the compound to the evaporation crucible. The part which evaporates will be replaced so that there is no draining off in the system. Another possibility is to have such a small gas flow that the total gas is saturated to the vapour pressure. Then the evaporation is independent from the filling level. In this case the evaporator and the gas flow must be optimized together.

\section{Literature}

11/ L.G.J. de Haart, Y.S. Lin, K.J. de Vries, A.J. Burggraaf; Solid State lonics, 47 (1991) 331

12/ G. Wahl in: Jahrbuch der Oberflächentechnik, Hüttinger Verlag, Heidelberg 1993

13/ F. Schmaderer, R. Huber, H. Oetzmann, G. Wahl; in: Proc. 11th Int. Conf. CVD, ed. by K.E. Spear and G.W. Cullen, ECS, Pennington, 1990, p.211-218

14/ J.P. Dismukes, B.J. Curtis; Silicon Conf., ECS, Princeton, 1973, p.258

15/ F. Schmaderer, R. Huber, H. Oetzmann, G. Wahl; in: Proc. 8th Europ. Conf. CVD, Glasgow, Scotland, 1991, ed. by M.L. Hitchman and N.J. Archer, p. 539-548

16/ W. Decker, A. Nürnberg, M. Pulver, R. Stolle, G. Wahl, Yu.Yu. Erokhin, O.Yu. Gorbenko, I.E. Graboy, A.R. Kaul, M. Sommer, U. Vogt; submitted to Proc. 12th Int. Conf. CVD, Honolulu, 1993

/7/ G. Wahl, S. Schlosser, W. Schmaderer, in: Proc. 7th Int. Conf. CVD, ed. by T.O. Sedgewick and H. Lydtin, ECS, Princeton, 1979, p. 536-548

/8/ R.C. Reid, J.M. Prausnitz, T.K. Sherwood, The Properties of Gases and Liquids, McGraw Hill, New York 1977

19/ A. likawa, M. Hira, Y. Kuniya; in: Extended Abstract of Spring Meeting of Japan Society of Applied Physics, 1991, No. 3, p.983

110/ E. Fitzer, H. Oetzmann, F. Schmaderer, G. Wahl; in: Proc. 8th Europ. Conf. CVD, Glasgow, Scotland, 1991, ed. by M.L. Hitchman and N.J. Archer, p. 713-720 

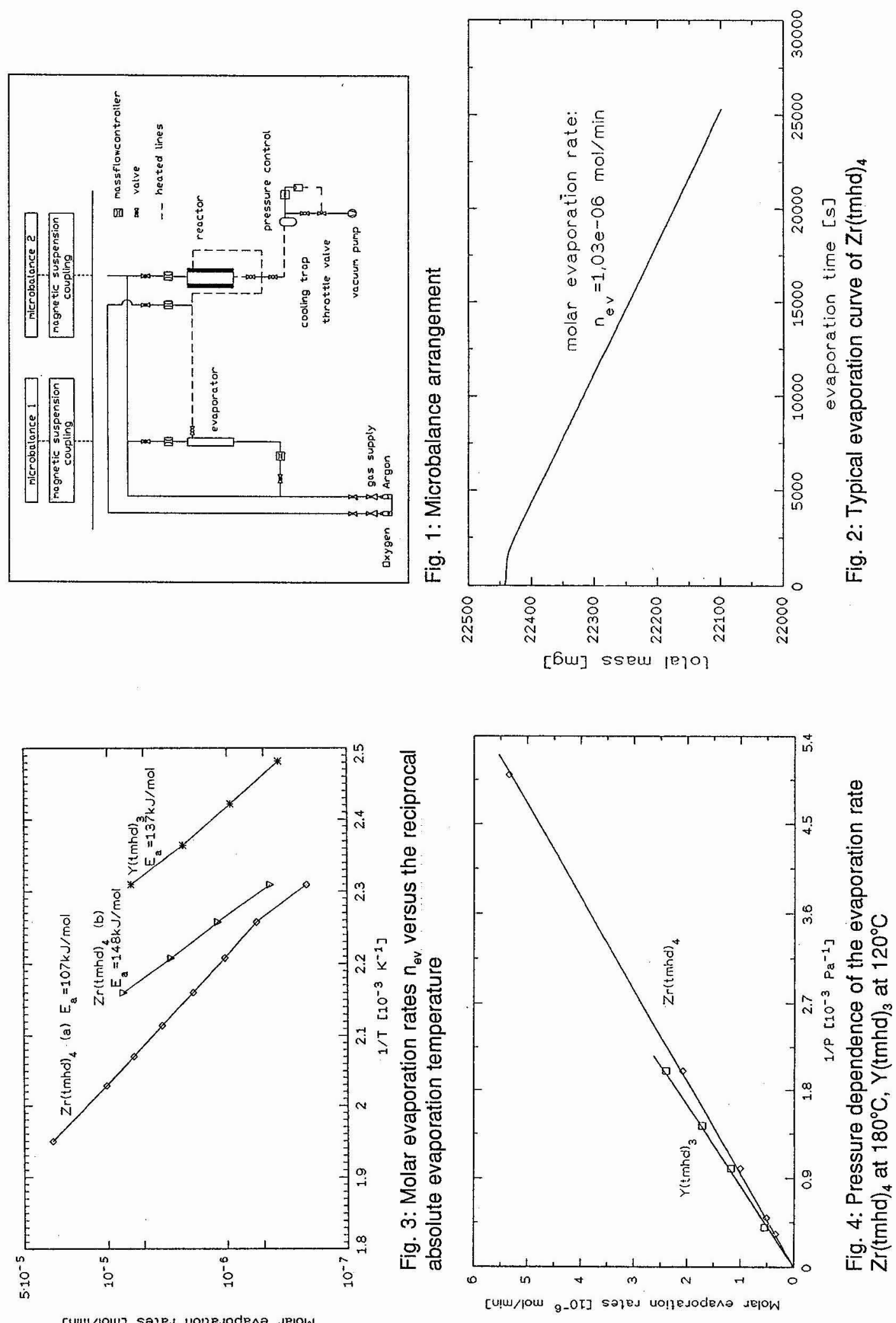

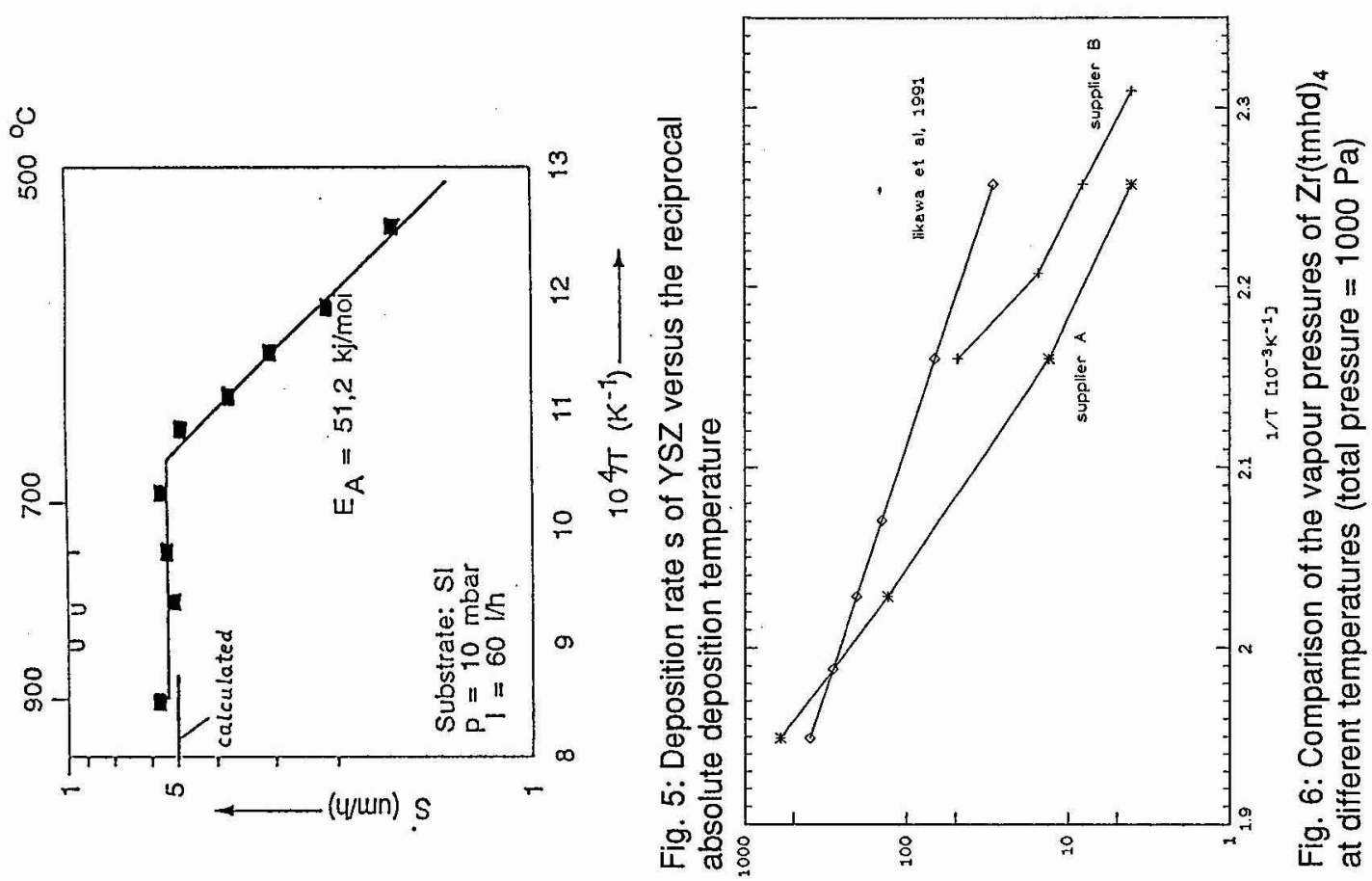

[ed]
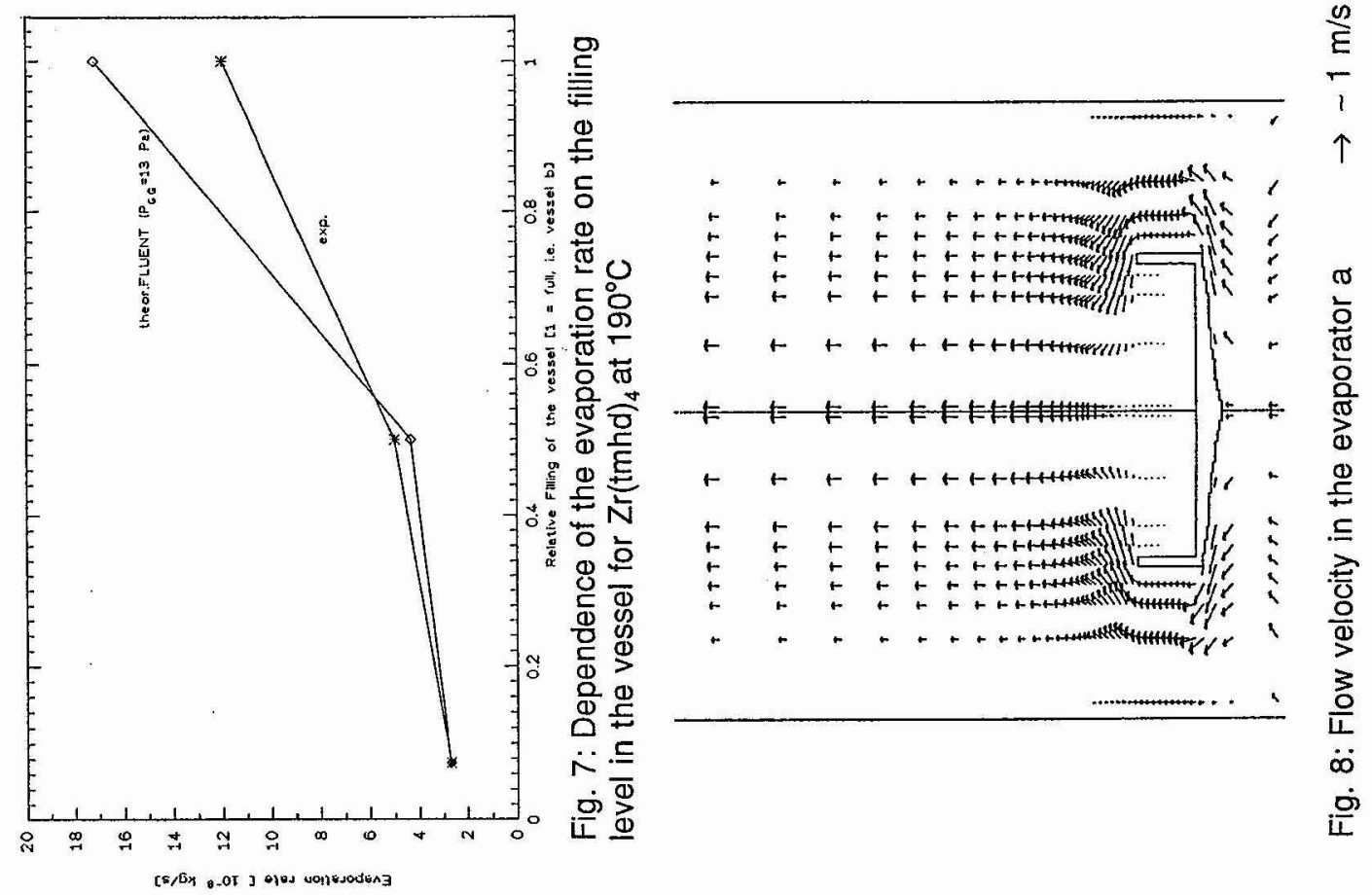